\title{
Movement of coat protein genes from a commercial virus-resistant transgenic squash into a wild relative
}

\author{
Marc FUCHS ${ }^{1 *}$, Ellen M. CHIRCO ${ }^{2}$ and Dennis GONSALVES ${ }^{1 * *}$ \\ ${ }^{1}$ Department of Plant Pathology, Cornell University, New York State Agricultural Experiment Station, Geneva, NY 14456, USA \\ ${ }^{2}$ Department of Horticultural Sciences, Cornell University, New York State Agricultural Experiment Station, Geneva, NY 14456, USA
}

\begin{abstract}
We monitored pollen-mediated transgene dissemination from commercial transgenic squash CZW-3 into its wild relative Cucurbita pepo ssp. ovifera var. texana (C. texana). Transgenic squash CZW-3 expresses the neomycin phosphotransferase II (nptII) gene and the coat protein (CP) genes of Cucumber mosaic virus (CMV), Zucchini yellow mosaic virus (ZYMV), and Watermelon mosaic virus (WMV); thereby, it is resistant to these three aphid-borne viruses. The rate of NPT II and CP transgene introgression increased with overlapping flowering patterns and a high ratio of transgenic $\mathrm{F} 1$ hybrids (C. texana $\times \mathrm{CZW}-3)$ to $C$. texana. Transgene transfer also readily occurred from transgenic $F 1$ hybrids into $C$. texana over three generations in field settings where test plants grew sympatrically and viruses were not severely limiting the growth, and fruit and seed production of C. texana. In contrast, introgression of the transgenes into $C$. texana was not sustained under conditions of high viral disease pressure. As expected, $C$. texana progeny that acquired the CP transgenes exhibited resistance to CMV, ZYMV, and WMV. This is the first report on transgene dissemination from a transgenic crop that exhibits disease resistance and hybridizes with a wild plant species without loss of fertility.
\end{abstract}

Key words: Environmental safety / risk assessment / pollen flow / transgenic squash / Cucurbita texana / coat protein gene / Cucumber mosaic virus / Zucchini yellow mosaic virus / Watermelon mosaic virus / neomycin phosphotransferase (NPT) II gene / introgression / enzyme-linked immunosorbent assay / engineered virus resistance

\section{INTRODUCTION}

The potential detrimental effects of gene flow from genetically modified plants to wild relatives is one of the major environmental safety issues being addressed with the commercialization of transgenic crops. Introgression of transgenes into wild and weedy relatives may turn wild plant species, i.e. plants that are growing and reproducing with no deliberate planting (Ellstrand et al., 1999), into noxious weeds, i.e. plants that interfere with human objectives (Ellstrand et al., 1999), in agricultural fields and natural habitats, and alter the ecological balance in centers of origin and diversity for plant species (Conner et al., 2003; Dale et al., 2002; Ellstrand et al., 1999; Gates, 1995; Hancock et al., 1996; Kareiva et al., 1994;
Kling, 1996; Rissler and Mellon, 1996; Snow and Palma, 1997; Tepfer, 2002).

Gene flow and introgression from cultivated plants into wild relatives has been extensively documented (Ellstrand et al., 1999). Similarly, gene introgression from transgenic crops into wild relatives has been reported. For example, Mikkelsen et al. (1996) analyzed the introgression of a transgene that confers tolerance to the herbicide glufosinate from transgenic oilseed rape (Brassica napus) into a wild relative (B. rapa). Fertile herbicide tolerant wild-type plants were obtained upon herbicide selection as early as the first backcross generation. Introgression also occurred from transgenic

\footnotetext{
* Corresponding author: fuchs@ colmar.inra.fr

Present address: Institut National de la Recherche Agronomique, Unité Mixte de Recherche Vigne et Vins d'Alsace, Laboratoire de Virologie, 28 rue de Herrlisheim, 68021 Colmar, France

** Present address: Pacific Basin Agricultural Research Center, PWA-ARS-USDA, 99 Aupuni Street, Ste 204, Hilo, Hawaii 96720, USA
} 
herbicide-resistant oilseed rape into wild radish (Raphanis raphanistrum L.) (Chèvre et al., 1997). In that study, herbicide-resistant interspecific hybrids developed but their number decreased in successive generations. In addition, four plant generations were needed to recover herbicide-resistant offsprings with characteristics (chromosome number and morphology) close to those of wild radish. More recently, the frequency of interspecific hybridization between transgenic oilseed rape and wild radish has been shown to be extremely low under field conditions (Chèvre et al., 2000). Similarly, a low outcrossing rate was reported for transgenic pea plants (Polowick et al., 2002). So far, no information is available on the introgression of virus-resistance traits from transgenic crops into wild relatives.

Squash (Cucurbita spp.) is a suitable model for studying the dissemination of transgenes that confer resistance to viruses because two virus-resistant transgenic crookneck squash (C. pepo ssp. ovifera var. ovifera) lines and derivatives of these lines have been deregulated and commercialized in the United States. Transgenic line $\mathrm{ZW}-20$ which expresses the coat protein $(\mathrm{CP})$ genes of Zucchini yellow mosaic virus (ZYMV) and Watermelon mosaic virus (WMV), and is resistant to these two viruses (Fuchs and Gonsalves, 1995; Tricoli et al., 1995) received exemption status in 1994 (Medley, 1994). Transgenic line CZW-3 which expresses the CP genes of Cucumber mosaic virus (CMV), ZYMV, and WMV, and is resistant to these three viruses (Fuchs et al., 1998; Tricoli et al., 1995) received exemption status in 1996 (Acord, 1996). Also, wild relatives of cultivated squash, including C. pepo ssp. ovifera var. texana (referred to here as $C$. texana), are commonly found in the Southern parts of the United States (Boyette et al., 1984; Decker, 1988; Nee, 1990; Oliver et al., 1983; Weidemann and Templeton, 1988). Furthermore, North, Central, and South America are the centers of origin and diversity for squash species (Wilson, 1990), and nontransgenic squash readily hybridize without loss of fertility to $C$. texana (Kirkpatrick and Wilson, 1988; Wilson and Payne, 1994). Recently, Spencer and Snow (2001) obtained fertile F1 hybrids of transgenic squash Freedom II, a derivative of transgenic line ZW-20, and $C$. texana. Based on some fitness components, these authors concluded that F1 hybrids do not represent strong barriers for gene flow from domesticated squash to C. texana. Thus, it is likely that gene flow will occur between transgenic squash CZW-3, which contains the CP genes of three distinct viruses and the marker gene neomycin phosphotransferase II (nptII) (Tricoli et al., 1995), and C. texana.
In this study, we assessed gene introgression from commercial transgenic squash CZW-3 into $C$. texana and analyzed consequent virus resistance in $C$. texana and their progeny under field conditions of high or low disease pressure by the three target viruses, i.e. CMV, ZYMV, and WMV.

\section{RESULTS}

\section{Characteristics of transgenic squash CZW-3 and C. texana}

Plants of the transgenic crookneck squash line CZW-3 were used as donors of transgenic pollen. They were hemizygous for the $\mathrm{CP}$ genes of CMV, ZYMV, and WMV, and resistant to these three aphid-borne viruses (Fuchs and Gonsalves, 1995; Tricoli et al., 1995). They also expressed the $n p t I I$ gene which cosegregates with the CP genes (Fuchs and Gonsalves, 1995; Tricoli et al., 1995). The wild squash species $C$. texana which is distributed in Texas (Boyette et al., 1984; Decker, 1988; Nee, 1990; Oliver et al., 1983; Weidemann and Templeton, 1988) was used as recipient of transgenic pollen. Plants of $C$. texana are susceptible to CMV, ZYMV, and WMV, and do not contain the nptII gene.

C. texana and transgenic squash CZW-3 are also distinctly different in their growth habit (viney $v s$. bushy) and fruit characteristics (Fig. 1A), including size (small $v s$. large), shape (round and oblate or pear-like vs. long and oblate with a curved neck), color (green with light green or white stripes vs. uniformly yellow), and flavor (bitter vs. fruity), as well as seed size (small vs. large) (Fig. 1B).

\section{Development and properties of F1 hybrids}

Our objective was to study gene introgression from transgenic squash CZW-3 into $C$. texana over two successive generations after an initial transfer of transgenes from CZW-3 to C. texana. The initial transfer of transgenes from transgenic squash CZW-3 into $C$. texana is likely to occur under field conditions because: (i) nontransgenic squash cultivars, including crookneck squash, and $C$. texana are sexually cross-compatible (Kirkpatrick and Wilson, 1988; Wilson, 1990; Wilson and Payne, 1994), (ii) pollen-mediated movement of native host genes and transgenes is known to be identical (Hokanson et al., 1997a), (iii) F1 hybrids of transgenic squash line Freedom II and C. texana are readily obtained (Spencer and Snow, 2001), and (iv) movement of pollen from cultivated transgenic squash seems inevitable 

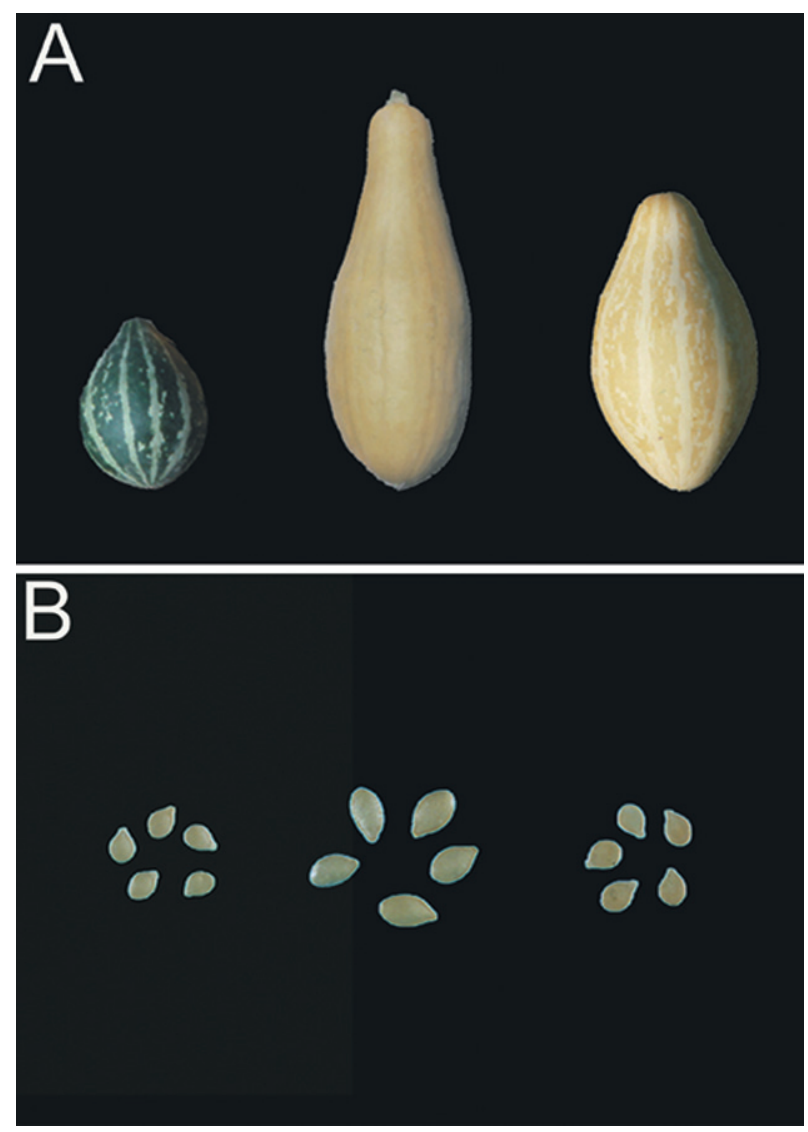

Figure 1. Typical features of $C$. texana (left), transgenic squash CZW-3 (middle), and F1 hybrids (C. texana $\times$ CZW-3) (right). (A) Comparative fruits size, shape, and color. (B) Comparative seed size. (This figure is available in color in electronic form at www.edpsciences.org/ebr).

(Hancock et al., 1996; Hokanson et al., 1997b; Kareiva et al., 1994; Metz et al., 1997; Spencer and Snow, 2001).

For this study, we produced F1 hybrids (C. texana $\times$ CZW-3) by hand pollination in the greenhouse using transgenic squash CZW-3 as staminate parent and C. texana as pistillate parent. Plants and fruits of F1 hybrids combined features of both parents in regard to fruit size (intermediate between small and large), fruit shape (oblong without a curved neck), fruit color (yellow with white stripes) (Fig. 1A), seed size (intermediate between small and large) (Fig. 1B), and growth habit (intermediate between bushy and viney). Measurement of shoot length on 40 field-grown plants in 1996 confirmed the latter differences with mean values of $31 \pm 6 \mathrm{~cm}$ for CZW-3, $89 \pm$ $13 \mathrm{~cm}$ for F1 hybrids, and $246 \pm 21 \mathrm{~cm}$ for C. texana.

Since the CZW-3 plants used as male parents were hemizygous for the $\mathrm{CP}$ and nptII transgenes, transgenic F1 hybrid plants were identified by detecting the expres- sion of the NPT II protein by enzyme linked-immunosorbent assay (ELISA) as described previously (Fuchs and Gonsalves, 1995; Fuchs et al., 1998; Tricoli et al., 1995). No apparent differences in plant morphology, vigor and fruit production were observed between transgenic and nontransgenic F1 segregants in the greenhouse (data not shown).

\section{Objectives and rationale of the field experiments}

Our field studies were designed to address four major questions: (1) Will introgression spontaneously occur with sympatric populations of transgenic F1 hybrids and C. texana? (2) Will flowering phenology of C. texana and transgenic F1 hybrids, and the ratio of transgenic F1 hybrids to $C$. texana influence the rate of transgene introgression? (3) Will the level of disease pressure, low vs. high, of the three target viruses, i.e. CMV, ZYMV, WMV, affect the rate of transgene introgression? and (4) Will the CP genes provide resistance against CMV, ZYMV, and WMV to C. texana progeny?

The experimental approach was to initially set replicated small-scale plantings of transgenic F1 hybrids surrounded by $C$. texana, so that the only source of transgenic pollen was from the transgenic F1 hybrids. Introgression of the transgenes was monitored by harvesting mature fruits of $C$. texana at the end of the growing season, extracting seeds, and assessing the expression of the NPT II protein in germinating seeds by ELISA.

Field experiments were performed over three consecutive years at the same sites, as described in the experimental protocol. To follow gene introgression over time, seeds harvested from randomly selected fruits at the end of a growing season were germinated in the spring of the following year, and seedlings were placed back at the same location where the fruits dropped the previous year. Hand pollination was not done in the field, thus, dispersal of pollen was through insect populations and wind.

\section{Overlapping flowering patterns and high ratio of transgenic $F 1$ hybrids to $C$. texana increase the rate of transgene introgression}

Preliminary experiments showed that F1 hybrids develop flowers sooner than $C$. texana and consequently produce fruits 1-2 weeks earlier (M. Fuchs and D. Gonsalves, unpublished observations). Similar observations were recently documented for F1 hybrids of Freedom II and C. texana (Spencer and Snow, 2001). To test whether flowering phenology would influence the rate of 


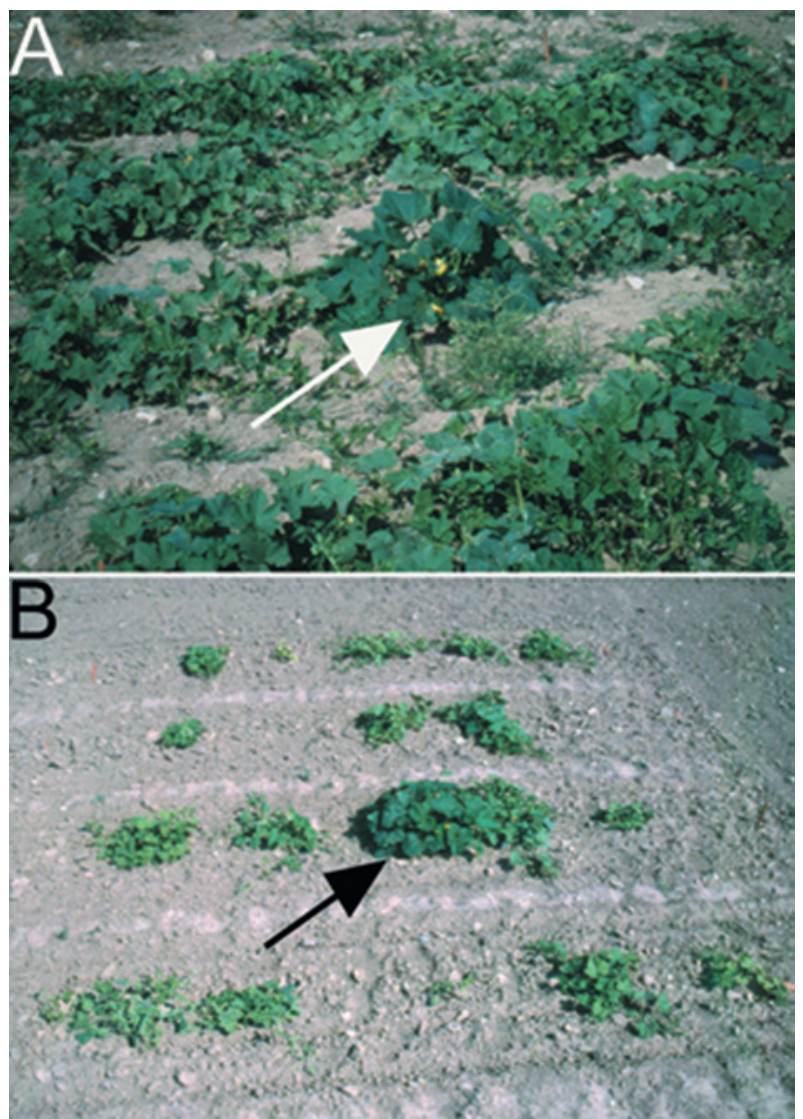

Figure 2. Vigor of 24 C. texana plants surrounding a single transgenic $\mathrm{F} 1$ hybrid $(C$. texana $\times \mathrm{CZW}-3)$ in the center of a $4 \times 10 \mathrm{~m}$ square block field. The position of the transgenic F1 hybrid is shown by an arrow. (A) Plants grown under conditions of low disease pressure by CMV, ZMV, and WMV. (B) Plants exposed to high disease pressure by CMV, $\mathrm{ZYMV}$, and WMV. (This figure is available in color in electronic form at www.edpsciences.org/ebr).

transgene introgression, four small square block plantings $(4 \times 8 \mathrm{~m})$ of $24 C$. texana were set with a single transgenic F1 hybrid in the center (Fig. 2A). Hybrids were transplanted either at the same time as $C$. texana in field A, or 1, 2, and 4 weeks later in fields B, C, and D, respectively (Tab. 1). A fifth field (E) was used to measure the fate of the transgenes in a setting of transgenic F1 hybrids.

The five fields (A-E) were kept under conditions of low disease pressure (LDP) by CMV, ZYMV, and WMV. These conditions were obtained by transplanting healthy plants in fields isolated from sources of aphidtransmissible viruses and by pulling out $C$. texana plants which exhibited viral symptoms (6\%, 6 of 96 plants) before the development of flowers (23-33 days post-
Table 1. Effect of transplanting time of $C$. texana and transgenic $\mathrm{F} 1$ hybrids $($ C. texana $\times \mathrm{CZW}-3)$ on the rate of introgression of the CP and NPT II transgenes.

\begin{tabular}{|c|c|c|c|c|}
\hline \multirow[b]{2}{*}{ Progeny } & \multirow[b]{2}{*}{ Field } & \multicolumn{3}{|c|}{ Transplanting Seed Progeny with Transgenes } \\
\hline & & Time $(w k s)^{1}$ & Positive/Tested $^{2}$ & $\%^{3}$ \\
\hline \multirow[t]{4}{*}{ C. texana } & A & 0 & $130 / 618$ & 21 \\
\hline & B & 1 & $246 / 746$ & 33 \\
\hline & $\mathrm{C}$ & 2 & $239 / 867$ & 28 \\
\hline & $\mathrm{D}$ & 4 & $89 / 558$ & 16 \\
\hline $\begin{array}{l}\text { Transgenic } \\
\text { F1 hybrids }\end{array}$ & $\mathrm{E}$ & 0 & $828 / 1064$ & 78 \\
\hline \multicolumn{5}{|c|}{$\begin{array}{l}{ }^{1} \text { Transgenic F1 hybrids were transplanted at the same time as }(0) \\
\text { or } 1-4 \text { weeks after } C \text {. texana. } \\
2 \text { Number of germinating seeds that were NPT II-positive in } \\
\text { ELISA over the total number of germinating seeds analyzed. } \\
\text { Approximately } 50 \text { randomly selected seeds were germinated for } \\
\text { each plant. The average seed germination rate was } 71 \text { and } 82 \% \\
\text { for } C \text {. texana and transgenic F1 hybrid progeny, respectively. } \\
{ }^{3} \text { Logistic regression models fitted to the data showed that overall } \\
\text { differences in fields A-D were significant }(P<0.001) \text {. Regression } \\
\text { analysis indicated a nonlinear relationship between transplanting } \\
\text { time (x) and rate of introgression }(y) \text { with increasing odds of intro- } \\
\text { gression by factors of } 1.84 \text { and } 1.43 \text { at } 1 \text { and } 2 \text { weeks, respectively, } \\
\text { and decreasing odds by a factor of } 0.7 \text { at } 4 \text { weeks. }\end{array}$} \\
\hline
\end{tabular}

transplanting). ELISA was used to measure the introgression of the nptII transgene, and presumably of the CP transgenes as well, in a number of randomly selected seeds from each plant.

Introgression of the CP and nptII transgenes into $C$. texana occurred in fields A-D (Tab. 1). The highest rate of introgression was observed in fields B (33\%) and C (28\%) where transgenic F1 hybrids were planted 1-2 weeks after $C$. texana. As expected, transgenic F1 hybrids in field $E$ had the highest percentage $(78 \%)$ of NPT II-positive progeny (Tab. 1). Overall differences among fields A-D were significant $(P<0.001)$. These results indicate that overlapping flowering patterns of C. texana and transgenic F1 hybrids increase the rate of introgression, although gene flow occurs regardless of differences in transplanting time between donors and recipients of transgenic pollen. Based on these results, subsequent field experiments were established by transplanting $C$. texana first and transgenic F1 hybrids one week later in order to maximize the rate of transgene introgression.

To analyze whether the number of donors of transgenic pollen would affect the rate of introgression, new field experiments were designed with a 1:8 (4 transgenic F1 hybrids and 32 C. texana) or a 1:24 (1 transgenic F1 hybrid and $24 C$. texana) ratio of transgenic F1 hybrids to C. texana in $5 \times 10$ and $4 \times 8 \mathrm{~m}$ square blocks, respectively. A control field with 25 transgenic F1 hybrids was also set. 
Virus-resistant transgenic squash hybridization

Table 2. Effect of disease pressure on fruit and seed production, seed germination, and rate of $\mathrm{CP}$ and nptII transgene introgression from transgenic $\mathrm{F} 1$ hybrids $(C$. texana $\times \mathrm{CZW}-3)$ into $C$. texana over three successive generations.

\begin{tabular}{lcccccccc}
\hline \hline C. texana & Year of & Virus & & Average & Average & \% Seed & \multicolumn{2}{c}{ Seed Progeny with Transgenes } \\
\cline { 8 - 9 } Progeny & Test $^{1}$ & Pressure $^{2}$ & No $^{3}$ & Fruits/Plant & Seeds/Fruit & Germination $^{4}$ & Positive/Tested $^{5}$ & $\%^{6}$ \\
\hline R0 (initial) & 1995 & low & 112 & $20 \pm 5$ & $196 \pm 75$ & 83 & $795 / 3637$ & 22 \\
& & high & 112 & $<1$ & $<1$ & 5 & $2 / 11$ & 18 \\
R1 (from 1995) & 1996 & low & 85 & $3 \pm 1$ & $176 \pm 54$ & 72 & $332 / 1097$ & 30 \\
& & high & 3 & 0 & 0 & 0 & $0 / 0$ & 0 \\
R2 (from 1996) & 1997 & low & 45 & $5 \pm 3$ & $219 \pm 87$ & 74 & $103 / 340$ & 30 \\
\hline
\end{tabular}

${ }^{1}$ Nontransgenic C. texana and transgenic F1 hybrids were planted in 1995 and fruits from these plants were analyzed. In 1996, seeds from randomly selected fruits harvested in 1995 were germinated and planted at the same sites. Subsequently, fruits from these plants were analyzed. In 1997, a similar experimental approach was used for seeds of fruits harvested in 1996. See experimental protocol for more details.

${ }^{2}$ Viral disease pressure from CMV, ZYMV, and WMV.

${ }^{3}$ Number of plants analyzed. Only C. texana and their progeny that were NPT II-negative in ELISA were selected for analysis of fruit and seed characteristics. All the plants were analyzed in 1995. The number of plants analyzed under conditions of LDP in 1996 and 1997 represented 20 and $25 \%$ of the total number of test plants, respectively. Plants were not analyzed under conditions of HDP in 1997 because viable seeds of $C$. texana progeny were not available in 1996.

${ }^{4}$ Ten seeds per fruit were analyzed from 1995 to 1997. In 1995, 10 randomly selected fruits were analyzed per C. texana plant. In 1996 and 1997, all fruits from selected plants were analyzed.

${ }^{5}$ Number of viable seeds that reacted positively for NPT II in ELISA over the total number of viable seeds tested.

${ }^{6}$ Regression analysis of the relationship between the ratio of donors $v s$. recipients of transgenic pollen and the rate of introgression indicated that the odds of transgene transfer increased by a factor of 2.3 in the $1: 8$ over the 1:24 plantings $(P<0.001)$.

Duplicated plantings were used for each treatment, e.g. 1:8 vs. 1:24 ratios, and controls. These were maintained under conditions of LDP by selecting field sites isolated from sources of aphid-transmissible viruses. Also, C. texana with viral symptoms (14\%, 16 of 112 plants) were eliminated early in the growing season to facilitate conditions of LDP. Randomly selected seeds (10 seeds/ fruit) from randomly selected fruits (10 fruits/plant) of C. texana were tested for the presence of the transgenes by NPT II ELISA.

Our data suggest a positive correlation between the number of source plants of transgenic pollen and the rate of transgene introgression. Indeed, the average percentage of NPT II-positive C. texana seed progeny was higher in fields with a 1:8 ratio $(29 \%, 810$ of 2746) than in those with a $1: 24$ ratio $(15 \%, 369$ of 2431$)$ treatment. These differences were significant $(P<0.001)$. As expected, a high percentage $(67 \%, 312$ of 468$)$ of the F1 hybrid offsprings were transgenic. Regression analysis of the relationship between the ratio of donors over recipients of transgenic pollen and the rate of introgression indicated that the odds of transfer increased by a factor of 2.3 in the 1:8vs. the 1:24 plantings $(P<0.001)$.

\section{High disease pressure of target viruses limits transgene introgression into C. texana}

To assess the effect of the level of disease pressure on the rate of introgression, and on the stability and perpetuation of the transgenes in C. texana, four replicated plantings of
C. texana and transgenic F1 hybrids were set in 1995 under conditions of LDP and high disease pressure (HDP) of the three target viruses. Conditions of LDP were achieved as described above and conditions of HDP were obtained by mechanically-inoculating $38 \%$ of the total number of $C$. texana that were transplanted with CMV, ZYMV, or WMV. Thus, under conditions of HDP, the three target viruses were present at an early development stage of the test plants. The presence of the transgenes was determined by NPT II ELISA in randomly selected seeds of randomly selected fruits of some test plants.

\section{5 field results of C. texana}

Introgression of the transgenes occurred in 1995 from transgenic $\mathrm{F} 1$ hybrids into the R0 C. texana population, i.e. the initial C. texana progeny, for both levels of disease pressure (Tab. 2). However, the magnitude of introgression was markedly lower under conditions of HDP compared with conditions of LDP with 2 of $11 \mathrm{vs}$. 795 of 3637 NPT II-positive seeds, respectively. This large difference was due to the fact that all of the $C$. texana plants became infected by viruses soon after transplanting under HDP settings, as a result of mechanical and aphid-mediated virus infection, as opposed to a limited number under LDP settings. Consequently, C. texana plants from HDP plots showed poor growth (Fig. 2B) and averaged less than one fruit per plant $v s$. succulent growth 
(Fig. 2A) and 20 fruits for C. texana plants in LDP plots (Tab. 2). In addition, fruits from plants grown under conditions of HDP averaged less than one viable seed while those from plants grown under conditions of LDP averaged nearly 200 viable seeds. The germination rate of seeds was $5 \%$ for fruits from HDP plots vs. $83 \%$ for fruits from LDP plots (Tab. 2).

All fruits of R0 C. texana plants from LDP plots were uniform in size (small), shape (round and oblate or pearlike), and color (green with light green or white stripes) while those from virus-infected plants in HDP plots were smaller in size and severely distorted.

\section{6 field results of C. texana progeny from 1995}

The R1 C. texana population, i.e. the first $C$. texana progeny, and transgenic F1 hybrids were subsequently tested in 1996 under conditions of LDP at the same sites by transplanting 3 randomly selected seedlings from randomly selected fruits (4 per plant) produced in 1995. Analysis of transplanted seedlings showed that 53\% (448 of 844) of them were positive for NPT II in ELISA. At the end of the growing season, all the fruits of randomly selected plants (20\%, 170 of 844 test plants) were harvested. To test for transgene introgression, 10 randomly selected seeds from plants that previously tested negative for NPT II in ELISA were germinated and subsequently assayed for NPT II expression. Our data showed the occurrence of transgene introgression to $30 \%$ of the 1097 tested seeds of the R1 C. texana generation (Tab. 2). Furthermore, the germination rate of seeds from fruits collected in LDP plots was high (72\%), although slightly lower than in 1995 (83\%) (Tab. 2).

The growth habits and fruit characteristics of some R1 C. texana also suggested the occurrence of introgression in the LDP plots. Examination of 398 fruits from C. texana progeny showed that $9 \%$ of them had untypical $C$. texana features with an oblong shape, yellow color, and white stripes.

In contrast, transgene introgression could not be measured in the HDP plots because only three seedlings were transplanted due to a very low number of seeds recovered from the 1995 HDP plots (Tab. 2). Moreover, these three plants did not produce mature fruits in 1996. Consequently, introgression of the transgenes was not further studied under conditions of HDP in 1997.

\section{7 field results of C. texana progeny from 1996}

Experiments were carried out in 1997 exclusively under conditions of LDP at the same sites by following the same approach as in 1996. Analysis of 428 transplanted seedlings indicated that $25 \%$ of them were transgenic, as determined by NPT II ELISA. At the end of the growing season, all the fruits from randomly selected nontransgenic (10\% of the 428 test plants) R2 C. texana plants, i.e. the second $C$. texana progeny, were harvested. Subsequently, 10 randomly selected seeds of each of these fruits were germinated and assayed for the presence of the transgenes. Our data indicated the occurrence of transgene introgression into $30 \%$ of the 340 tested seeds (Tab. 2).

Transgene introgression into the $\mathrm{R} 2 C$. texana was also substantiated by the segregation of the fruit characteristics (Fig. 3). Of the 391 fruits examined, $34 \%$ of them were not typical of $C$. texana as compared with only $9 \%$ in 1996 . Fruits showed a marked variability in size (small or large), shape (pear-like or oblong), and color (green or yellow with white stripes) (Fig. 3) whereas those of R0 C. texana were uniformly small and green with a round or pear-like shape, and white stripes. As observed for the R1 C. texana in 1996, the R2 generation averaged in 1997 much fewer fruits than the R0 C. texana in 1995 (5 vs. 20) (Tab. 2).

\section{5-1997 field results of F1 hybrids and their progeny}

The same data taken on C. texana and their progeny were also evaluated for F1 hybrids and their progeny. In 1995, only transgenic F1 hybrids were transplanted. Analysis of the transplanted seedlings in 1996 and 1997 indicated that 58 of the $72(81 \%)$, and 11 of $15(73 \%)$ plants were transgenic, respectively. As expected, the level of disease pressure did not affect the percentage of seeds of F1 hybrids offsprings that were NPT II-positive in ELISA [52\% (449 of 870) vs. 56\% (204 of 364) in LDP and HDP settings, respectively]. Furthermore, the mean production of fruits $(3 \pm 2 v s .3 \pm 1)$ and seeds $(227 \pm 45 v s .240 \pm$ $56)$, as well as the rate of seed germinability (81 vs. 83\%), were similar for plants from LDP and HDP plots.

Fruits from transgenic F1 hybrids and their progeny were mostly oblong and yellow with white stripes, even for the 1997 trial (Fig. 1A).

\section{Introgression of the CP transgenes provides resistance against CMV, ZYMV, and WMV to C. texana progeny}

The reaction of $C$. texana and their progeny to aphidmediated infections by CMV, ZYMV, and WMV was 


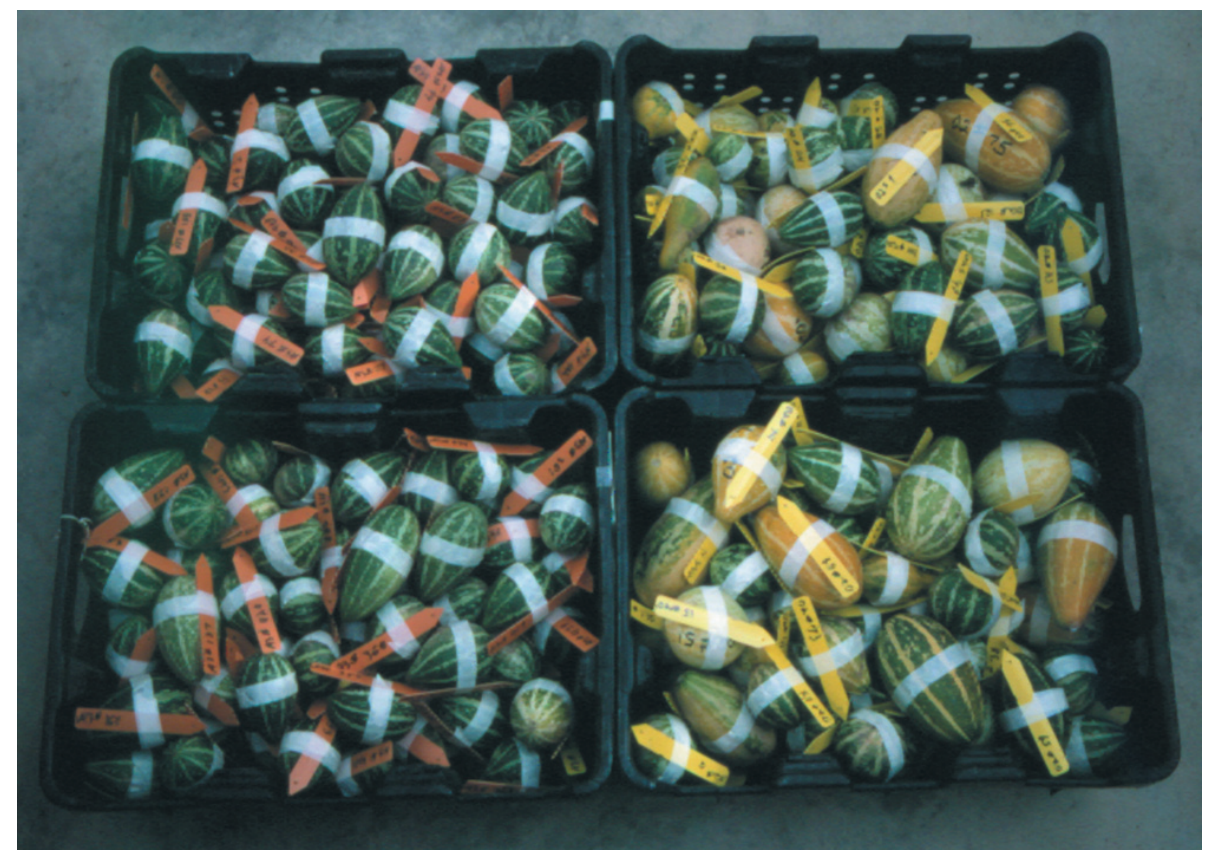

Figure 3. Comparative analysis of the fruits of $\mathrm{R} 0$ and $\mathrm{R} 2$ C. texana progeny. Fruits of $\mathrm{R} 0$ C. texana are uniform in size, shape, and color (2 logs on the left) whereas fruits of R2 C. texana show a broad diversity in size, shape, and color (2 logs on the right) due to segregation after efficient cross-pollination. (This figure is available in color in electronic form at www.edpsciences.org/ebr).

analyzed under conditions of LDP and HDP from 1995 to 1997. Virus resistance, measured as a failure to systemically infect test plants, was evaluated by visual monitoring of symptom development and by ELISA detection of CMV, ZYMV, and WMV.

Disease progress curves of C. texana in 1995 showed that $100 \%$ of them were symptomatic under HDP conditions within 32 days after transplanting, compared with less then $10 \%$ at the same time period under LDP conditions (Fig. 4A). The number of $C$. texana that became symptomatic in the LDP plots increased moderately until all of them were symptomatic at 75 days after transplanting. Systemic symptoms consisted of foliar mosaic, chlorosis, shoe-stringing, downward curling, and stunted growth. ELISA data confirmed the high incidence of CMV, ZYMV, and WMV in virussusceptible plants (data not shown).

Disease progress curves of the R1 and R2 transgenic C. texana progeny indicated no symptom development throughout the growth cycle of 72 or 96 days in 1996 (Fig. 4B) and 1997 (Fig. 4C), respectively, except for a few of them at the end of the trial periods. In contrast, $c a$. $65 \%$ of the nontransgenic $C$. texana counterparts developed symptoms at the end of the growth cycles (Fig. 4B and C). Unlike the comparable LDP trials in 1995, the symptomatic C. texana progeny did not appear until 42 to 48 days after transplanting in 1996 and 1997, respectively, and the rate of infected plants was lower than in 1995 (65 vs. 100\%). This lower percentage is probably because the higher number of transgenic C. texana progeny in 1996 and 1997, compared with 1995, reduced the inoculum pressure.

Mechanical inoculation by ZYMV of some randomly selected $C$. texana progeny in the greenhouse indicated that the majority of NPT II-positive individuals remained symptomless $(96 \%, 99$ of 103$)$ or showed mild symptoms (4\%, 4 of 103). Contrary, all of the mechanicallyinoculated NPT II-negative C. texana progeny from 1997 $(100 \%, 144$ of 144) were symptomatic with severe mosaic and leaf deformation. These data indicate that C. texana progeny, which acquire $\mathrm{CP}$ transgene, exhibit virus resistance upon exposure to high disease pressure provided either by mechanical or aphid-mediated infection.

In contrast, during the 1995-1997 trials, transgenic F1 hybrids and their progeny did not develop systemic symptoms upon infection by CMV, ZYMV, and WMV, regardless of the level of disease pressure (Fig. 4D).

A few transgenic F1 hybrids in 1995 (20\%) (Fig. 4D) and NPT II-positive C. texana offsprings in 1996 (4\%) (Fig. 4B) and 1997 (8\%) (Fig. 4C) developed systemic symptoms of mosaic and chlorosis, suggesting the presence of one or more different viruses than those which supplied the three CP transgenes. ELISA was subsequently used to identify the causative agents among cucurbit-infecting viruses, and the aphid-borne Papaya ringspot virus and the nematode-borne Tomato ringspot virus were detected. 

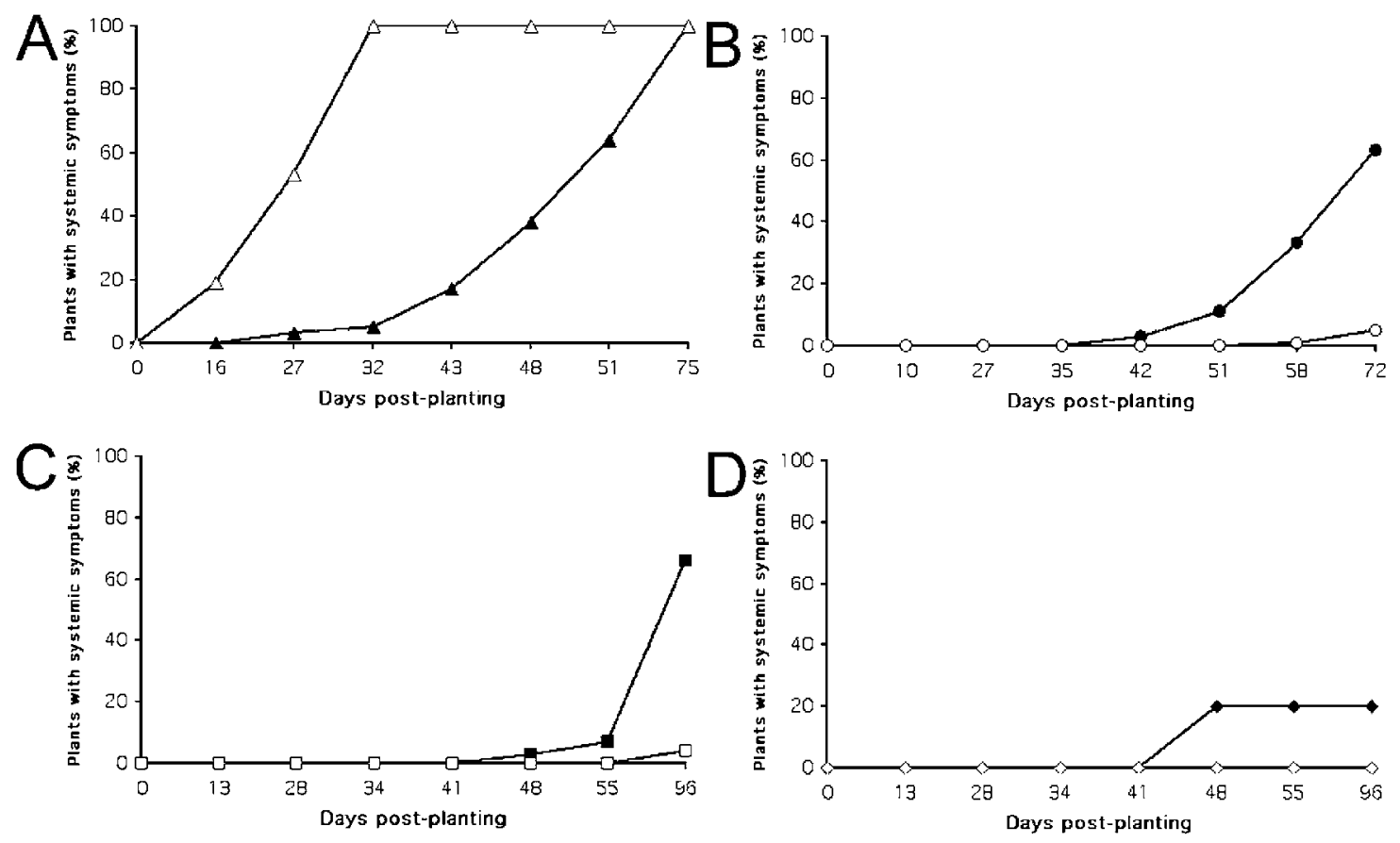

Figure 4. Disease progress curves on $C$. texana and $C$. texana progeny over three consecutive years. (A) R0 C. texana under conditions of low $(\boldsymbol{\Delta})$ and high disease pressure $(\triangle)$ in 1995. (B) R1 transgenic $(\mathrm{O})$ and nontransgenic $(\bullet) C$. texana progeny exposed to low disease pressure in 1996. (C) R2 transgenic ( $\square$ ) and nontransgenic ( $\boldsymbol{\square}$ ) C. texana progeny under settings of low disease pressure in 1997. (D) Transgenic F1 hybrids (C. texana $\times$ CZW-3) exposed to high $(\diamond)$ and low disease pressure $(\diamond)$ from 1995 to 1997 . F1 hybrid progeny reacted similarly from 1995 through 1997 in plots of low disease pressure.

\section{DISCUSSION}

Introgression of CP transgenes into wild relatives is an environmental safety issue associated to the release of virus-resistant transgenic crops since wild-crop hybrid progeny exhibiting increased fitness or eventually enhanced aggressiveness and invasiveness may result from the expression of the virus resistance traits (Dale et al., 2002; Kling, 1996; Rissler and Mellon, 1996). In fact, this concern was raised before transgenic squash lines ZW-20 and CZW-3 were deregulated by APHISUSDA because wild squash species, including $C$. texana, are reported as weeds in various localities in the Southern parts of the United States (Boyette et al., 1984; Decker, 1988; Nee, 1990; Oliver et al., 1983; Spencer and Snow, 2001; Weideman and Templeton, 1988). In reference to USDA's action to deregulate transgenic squash lines ZW-20 and CZW-3, a recent report by the Committee on Genetically Modified Pest-Protected Plants of the National Research Council (NRC) concluded that "USDA's assumption that transgenic resistance to viruses will not affect the weediness of wild $C$. pepo might be correct, but longer-term empirical studies are needed to determine whether this is true" (National Research Council, 2000). Our work clearly documents the transfer of virus resistance traits from transgenic F1 hybrids of CZW-3 and C. texana into C. texana over three generations when the plants are in close spatial proximity and viruses are not severely limiting the growth and reproduction of $C$. texana. In contrast, introgression of the transgenes into $C$. texana was not sustained under conditions of HDP. The latter conditions are unlikely to be consistently present throughout the United States, particularly in the Southern parts. Thus, based on our data, we can anticipate that movement of virus resistance traits from commercial transgenic squash CZW-3 into C. texana is likely to occur under natural conditions. Similar conclusions were drawn from fecundity studies of F1 hybrids of transgenic Freedom II and C. texana (Spencer and Snow, 2001).

As was also pointed out in the NRC's report (National Research Council, 2000) and by others (Barstch and 
Schuphan, 2002; Jenczewski et al., 2003), the most important environmental safety issue is not so much the occurrence but rather the consequences of introgression of the virus resistance traits. A potential risk is, for example, that CMV, ZYMV, or WMV are limiting the growth and reproduction of $C$. texana in natural habitats. Consequently, the fitness components and eventually the potential weediness of $C$. texana might be enhanced upon introgression of the $\mathrm{CP}$ genes. As our data clearly show, the three target viruses are capable of limiting the growth and fruit production of $C$. texana in experimental HDP settings. Therefore, once the virus resistance traits have introgressed into a wild squash population, some of the C. texana progeny will exhibit virus resistance. As a result, some fitness characteristics of those individuals, and possibly their weediness potential, might increase under high viral disease pressure.

Large scale surveys to determine the effect of viruses on C. texana in natural habitats have not been completed yet. Interestingly, however, preliminary surveys of 14 sites in Mississippi, Louisiana, and Arkansas did not suggest that viruses, including the three target viruses of our study, are prevalent or even present in wild squash populations (Quemada, 1998). More recent surveys of 38 additional sites confirm these early results (Quemada et al., 2002). As more data become available on the incidence of viruses in natural habitats of $C$. texana, environmental risks will be assessed more precisely and management strategies devised, if necessary, to reduce their impact. Then, risk of enhanced weediness in wild squash and benefits of controlling viruses in cultivated squash will need to be weighed in the process of determining what, if any, changes in regulation, may need to be implemented. The implications of our findings directly relate to transgenic but also to nontrangenic virus-resistant squash because it is the virus resistant trait, whether conferred by a transgene or a host gene, that has the potential to be transferred into wild $C$. texana populations.

Hybridization plays an important role on the evolution of invasiveness (Ellstrand and Schierenbeck, 2000). Will virus resistance turn $C$. texana into a more aggressive and more invasive weed? In addition to virus resistance, other characteristics determine the relative ability of a plant to become a noxious weed. In the case of C. texana, it is assumed that this wild squash species has reached its equilibrium in terms of its potential weediness. Some of the weediness characteristics of C. texana are (Boyette et al., 1984; Oliver et al., 1983; Weideman and Templeton, 1988): (i) their tough gourd which interferes with harvester machineries, (ii) the buoyant gourds that are widely distributed during floods, and (iii) the persistent seeds which can stay in the ground for several years and germinate once disturbed. C. texana progeny resulting from introgression of the $\mathrm{CP}$ genes will have altered growth characteristics (plant vigor, reproductive potential, etc), besides virus resistance, that might be of advantage - or disadvantage - as a weed. These characteristics are expected to change as dissemination of transgenes progresses over several backcross generations. To evaluate the dynamics of these changes, we compared the fitness of $C$. texana and three consecutive generations of hybrids between commercial transgenic squash CZW-3 and C. texana in regard to virus resistance, plant vigor, and reproductive potential. Our results are presented and discussed in a companion paper (Fuchs et al., 2004).

Gene flow between cultivated and wild squash has probably occurred for a very long time in North America, likely since the domestication of squash which has been traced back to 100 centuries ago (Smith, 1997). Cultivated and wild squash species have co-existed and co-evolved, in particular in the South central States in the United States where squash production fields are located near natural habitats of wild relatives, including C. texana. Chloroplast DNA diversity (Wilson, 1990; Wilson et al., 1992), allozyme frequency distribution (Decker-Walters et al., 1993; Smith, 1997; Wilson, 1990; Wilson et al., 1992), and distinctive patterns of variation in fruit structure, color, and bitterness in populations of wild squash clearly indicate that past hybridization and introgression has resulted in permanent gene transfer from cultivated into wild squash.

Flowering phenology and the ratio of transgenic F1 hybrids over $C$. texana affected the rate of transgene introgression, although to a much lesser extent than disease pressure of target viruses (this study). Others have also reported on the increased frequency of transgene introgression with higher ratios of donor to recipient plants of transgenic pollen (Hokanson et al., 1997a). In our experimental field settings, donor and recipient plants grew sympatrically. Under natural field conditions, however, a myriad of conditions which differ from those of our semi-managed conditions will affect the dissemination of transgenes: local abundance and geographic distribution of C. texana in natural habitats, distance between donors and recipient of transgenic pollen, absence of flowering synchrony, dynamics of pollen vectors, climatic conditions, seed dormancy, fitness costs and barriers, invasiveness potential, etc. Nevertheless, our data seem to clearly suggest that virus pressure on the recipient plants is a critical factor that 
influences flowering/fruiting, and hence the magnitude of transgene introgression into wild squash.

\section{MATERIALS AND METHODS}

\section{Plant material}

Transgenic squash line CZW-3 was obtained by Agrobacterium tumefaciens-mediated transformation (Tricoli et al., 1995). The transgenic line CZW-3 used in this study was a hybrid progeny resulting from a cross of a transgenic line homozygous for the $\mathrm{CP}$ and nptII transgenes and a nontransgenic parent. Seeds from natural populations of the geographically restricted C. texana were from the North Central Regional Plant Introduction Station in Ames, IA, USA. F1 hybrids (C. texana $\times \mathrm{CZW}-3$ ) were developed by hand pollination using one male flower per stigma after bagging female flowers.

\section{Mechanical inoculations of $C$. texana}

Mechanical inoculations of $C$. texana were performed in the greenhouse with CMV strain Fny, ZYMV strain FL, or WMV strain NY on 15-18 day-old plantlets showing two fully expanded leaves and a third one emerging as described previously (Fuchs and Gonsalves, 1995; Fuchs et al., 1998).

\section{Field layout}

Replicated field experiments were set from June to October in 1995, 1996, and 1997 on four different farms in Geneva, NY, USA under permits issued by APHISUSDA in 1995 and 1996. No permit was necessary in 1997 because transgenic line CZW-3 was deregulated in 1996 (Acord, 1996). Seedlings were transplanted $1 \mathrm{~m}$ apart and $2 \mathrm{~m}$ within rows. Field plots were tilled in 1995 but not in 1996 and 1997. Hand weeding was done each year during the trial period. No insecticides were used in order to monitor the plant reaction to aphid-mediated virus infection. To prevent pollen contamination of our test plants from source plants outside our experimental fields, all plots were isolated from other squash plantings by at least $1000 \mathrm{~m}$. If several sites were used on the same farm, our settings were at least $50 \mathrm{~m}$ apart, and maintained under conditions of either low disease pressure (LDP) or high disease pressure (HDP).

\section{Experimental design}

Field trials were designed to assess how the rate of transgene introgression is affected by the following factors: (1) differences in transplanting time between transgenic F1 hybrids and C. texana, (2) the ratio of transgenic F1 hybrids over C. texana, and (3) the level of disease pressure by CMV, ZYMV, and WMV.

The effect of transplanting time on the rate of transgene introgression was studied in field settings where transgenic F1 hybrids were transplanted either at the same time as C. texana or 1-4 weeks later. Field plots were maintained under conditions of LDP. These conditions were obtained by transplanting healthy plants at locations isolated from sources of aphid-vectored viruses. In addition, plants that became infected early in the season, e.g. before the development of flowers, due to viruliferous aphids arriving from outside of our fields, were eliminated to keep the virus incidence as low as possible.

The effect of the ratio of transgenic F1 hybrids over C. texana on the rate of transgene introgression was examined in field settings where 1 or 4 transgenic F1 hybrids were surrounded by 24 and 32 C. texana, respectively. Field plots were maintained under LDP.

The effect of viral disease pressure on the rate of transgene introgression was evaluated over time in field settings maintained under conditions of LDP or HDP. Conditions of HDP were achieved by transplanting a number of $C$. texana that were mechanically inoculated with CMV, ZYMV or WMV. These inoculated plants were transplanted at determined locations ( 1 or 2 plants per row) to facilitate an uniform distribution of CMV, ZYMV, and WMV throughout each field. To study the effect of disease pressure over time at the same sites, fruits were individually labeled in 1995 and a stake was placed at the location where they dropped. Seeds were subsequently extracted and cleaned. In the spring of 1996, randomly selected seeds (6 seeds/fruit) of four randomly selected fruits per plant were germinated. Seeds were sown directly in partitioned flats containing artificial growing medium and allowed to develop for 15-20 days in a screenhouse before transplanting. From each group of 6 seedlings, 3 were selected at random and transplanted at the same location where the fruits were formed in 1995. The same sequence was used in 1997 with the progeny of 1996. The presence of the transgenes in transplanted seedlings was not known at the time of transplanting. Subsequently, cotyledon samples from transplanted seedlings were tested for expression of the NPT II protein by ELISA to identify which test plants contained the transgenes. 


\section{Data collection}

Test plants were monitored for fruit and seed production, and for virus resistance. In 1995, all the plants were tested. In 1996 and 1997, only 20 and $25 \%$ of the test plants, respectively, were randomly selected throughout each field and analyzed. Half of the test plants which were scored in 1996 and 1997 did not contain the transgenes, as determined by NPT II ELISA.

The rate of transgene introgression was obtained by calculating the number of NPT II-positive seedlings arising from nontransgenic $C$. texana progeny over the total number of seedlings tested.

\section{Seed extraction, count, and germination}

Fruits were maintained on the plants for at least 60 days between flowering and harvest. In the fall of each year, fruits were harvested and stored at least 4 weeks for ripening. Then, seeds were extracted, cleaned, and air dried. Immature seeds were sorted out and eliminated using a blower that creates a vertically-oriented air turbulence inside a polypropylene chamber, thus providing conditions for seed selection based on weight. Light immature seeds were blown up and collected in upper side compartments of the chamber while heavy mature seeds stayed in the bottom. Viable seeds were subsequently counted by hand and germinated on wet filter paper in incubators with controlled temperature $\left(15 \mathrm{~h}\right.$ at $20^{\circ} \mathrm{C}$ and $9 \mathrm{~h}$ at $30^{\circ} \mathrm{C}$ ) and high relative humidity $(100 \%)$.

\section{NPT II ELISA}

Seedlings were tested for expression of the marker gene NPT II by ELISA using commercial $\gamma$-globulins (5 Prime $\rightarrow 3$ Prime, Boulder, CO, USA). Samples of cotyledon tissue were collected on 5-day-old seedlings, soaked overnight in extraction buffer, and used as antigen in ELISA as described previously (Fuchs and Gonsalves, 1995; Fuchs et al., 1998; Tricoli et al., 1995).

\section{Plant reaction to virus infection}

Plant reaction to virus infection was evaluated by visual monitoring of symptom development at regular time intervals, and by ELISA using antibodies developed in our laboratory as described previously (Fuchs and Gonsalves, 1995; Fuchs et al., 1998; Tricoli et al., 1995).

\section{Statistical analyses}

Data on the effect of transplanting time, ratio of transgenic F1 hybrids over C. texana, and disease pressure on the rate of transgene introgression were analyzed. To detect treatment differences and study the relationship between variables, analysis of variance, multivariate analysis, and regression analysis were conducted using SAS ${ }^{\circledR}$ (Statistical Analysis System, SAS Institute Inc., Raleigh, NC, USA).

\section{ACKNOWLEDGMENTS}

We thank Dr. Dave Tricoli of the Asgrow Seed Company for providing us with seeds of transgenic squash CZW-3 and C. texana. We are grateful to Sheri Ecker-Day, Vânia Souza, Judy Alcock, and George Mittak for their excellent help, as well as to William Boone and Jonathan Douglas. We thank Dr. John Barnard for the statistical analyses, Drs. L.M. Yepes and H. Quemada for critically reading the manuscript, and Peggy Andret and Emmanuelle Vigne for assistance with artwork. This work was partially supported by a competitive grant from USDA's Biotechnology Risk Assessment Research Grants Program (No 95-33120-1878). This manuscript is dedicated to the memory of George Mittak who suddenly passed away in November of 2001.

Received August 25, 2003; accepted December 15, 2003.

\section{REFERENCES}

Acord BD (1996) Availability of determination of nonregulated status for a squash line genetically engineered for virus resistance. Fed. Reg. 61: 33484-33485

Barstch D, Schuphan I (2002) Lessons we can learn from ecological biosafety research. J. Biotech. 98: 71-77

Boyette DC, Templeton GE, Oliver LR (1984) Texas gourd (Cucurbita texana) control with Fusarium solani f. sp. cucurbitae. Weed Sci. 32: 649-655

Chèvre AM, Eber F, Baranger A, Renard M (1997) Gene flow from transgenic crops. Nature 389: 924

Chèvre AM, Eber F, Darmency H, Fleury A, Picault H, Letanneur JC, Renard M (2000) Assessment of interspecific hybridization between transgenic oilseed rape and wild radish under normal agronomic conditions. Ther. Appl. Genet. 100: 1233-1239

Conner AJ, Glare TR, Nap JP (2003) The release of genetically modified crops in the environment. Part II. Overview of ecological risk assessment. The Plant J. 33: $19-46$ 
Dale PJ, Clarke B, Fontes EMG (2002) Potential for the environmental impact of transgenic crops. Nature Biotech. 20: $567-574$

Decker DS (1988) Origin(s), evolution, and systematics of Cucurbita pepo (Cucurbitaceae). Econ. Bot. 42: 4-15

Decker-Walters DS, Walters TW, Cowan CW, Smith BD (1993) Isozymic characterization of wild populations of Cucurbita pepo. J. Ethnobiol. 13: 55-72

Ellstrand NC, Schierenbeck KA (2000) Hybridization as a stimulus for the evolution of invasiveness in plants? Proc. Natl. Acad. Sci. USA 97: 7043-7050

Ellstrand N, Prentice HC, Hancock JF (1999) Gene flow and introgression from domesticated plants into their wild relatives. Annu. Rev. Ecol. Syst. 30: 539-563

Fuchs M, Gonsalves D (1995) Resistance of transgenic hybrid squash ZW-20 expressing the coat protein genes of zucchini yellow mosaic virus and watermelon mosaic virus 2 to mixed infections by both potyviruses. Bio/Tech. 13: 1466-1473

Fuchs M, Tricoli DM, McMaster JR, Carney KJ, Schesser M, McFerson JR, Gonsalves D (1998) Comparative virus resistance and fruit yield of transgenic squash with single and multiple coat protein genes. Plant Dis. 82: 1350-1356

Fuchs M, Chirco EM, McFerson JR, Gonsalves D (2004) Comparative fitness of a wild squash species and three generations of hybrids between wild $\times$ virus-resistant transgenic squash. Environ. Biosafety Res. 3: 17-28

Gates P (1995) The environmental impact of genetically engineered crops. Biotech. Gen. Eng. Rev. 13: 181-195

Hancock JK, Grumet R, Hokanson SC (1996) The opportunity for escape of engineered genes from transgenic crops. HortScience 31: 1080-1085

Hokanson SC, Hancock JF, Grumet R (1997a) Direct comparison of pollen-mediated movement of native and engineered genes. Euphytica 96: 397-403

Hokanson SC, Grumet R, Hancock JF (1997b) Effect of border rows and trap/donor ratios on pollen-mediated gene movement. Ecol. Appl. 7: 1075-1081

Jenczewski E, Ronfort J, Chèvre AM (2003) Crop-to-wild gene flow, introgression and possible fitness effects of transgenes. Environ. Biosafety Res. 2: 9-24

Kareiva P, Morris W, Jacobi CM (1994) Studying and managing the risk of cross-fertilization between transgenic crops and wild relatives. Mol. Ecol. 3: 15-21

Kirkpatrick KJ, Wilson H (1988) Interspecific gene flow in Cucurbita: C. texas vs. C. pepo. Am. J. Bot. 75: 519-527

Kling J (1996) Could transgenic supercrops one day breed superweeds? Science 274: 180-181

Medley TL (1994) Availability of determination of nonregulated status for virus resistant squash. Fed. Reg. 59: 64187-64189

Metz PLJ, Jacobsen E, Nap JP, Pereira A, Stiekema WJ (1997) The impact on biosafety of the phosphinothricintolerance transgene in inter-specific $B$. rapa $\times B$. napus hybrids and their successive backcrosses. Theor. Appl. Genet. 95: $442-450$
Mikkelsen TR, Andersen B, Jørgensen RB (1996) The risk of crop transgene spread. Nature 380: 31

National Research Council (2000) Genetically modified pest-protected plants: Science and regulation. National Academy Press, Washington DC, http://www.nap.edu/books/ 0309069300/html/index.html

Nee M (1990) The domestication of Cucurbita (Cucurbitaceae). Econ. Bot. 42: 4-15

Oliver LR, Harrison SA, McClelland M (1983) Germination of Texas gourd (Cucurbita texana) and its control in soybean (Glycine max). Weed Sci. 31: 700-706

Polowick PL, Vandenberg A, Mahon JD (2002) Field assessment of outcrossing from transgenic pea (Pisum sativum L.) plants. Transgenic Res. 11: 515-519

Quemada H (1998) The use of coat protein technology to develop virus-resistant cucurbits. In Ives CL \& Bedford $\mathrm{BM}$, eds, Agricultural Biotechnology in International Development, CAB International, Wallingford, UK, pp 147160

Quemada H, Strehlow L, Decker-Walters D, Staub J (2002) Case Study: Gene flow from commercial transgenic Cucurbita pepo to "wild" C. pepo populations. In Proceedings of the Scientific Methods Workshop on Ecological and Agronomic Consequences of Gene Flow from Transgenic Crops to Wild Relatives, March 5-6, 2002, Columbus, OH, pp 65-70, http://www.biosci.ohio-state.edu/ lspencer/gene_flow.htm

Rissler J, Mellon M (1996) The Ecological Risks of Engineered Crops, MIT Press, Cambridge, MA

Smith BD (1997) The initial domestication of Cucurbita pepo in the Americas 10000 years ago. Science 276: 932-934

Snow AA, Palma PM (1997) Commercialization of transgenic plants: Potential ecological risks. BioScience 47: 86-96

Spencer LJ, Snow A (2001) Fecundity of transgenic wild-crop hybrids of Cucurbita pepo (Cucurbitaceae): implications for crop-to-wild gene flow. Heredity 86: 694-702

Tepfer M (2002) Risk assessment of virus-resistant transgenic plants. Annu. Rev. Phytopathol. 40: 467-491

Tricoli DM, Carney KJ, Russell PF, McMaster JR, Groff DW, Hadden KC, Himmel PT, Hubbard JP, Boeshore ML, Quemada HD (1995) Field evaluation of transgenic squash containing single or multiple virus coat protein gene constructs for resistance to cucumber mosaic virus, watermelon mosaic virus 2 , and zucchini yellow mosaic virus. Bio/Tech 13: 1458-1465

Weidemann GJ, Templeton GE (1988) Efficacy and soil persistence of Fusarium solani f. sp. cucurbitae for control of Texas gourd (Cucurbita texana). Plant Dis. 72: 36-38

Wilson HD (1990) Gene flow in squash species. BioScience 40: 449-455

Wilson HD, Payne JS (1994) Crop/weed microgametophyte competition in Cucurbita pepo (Cucurbitaceae). Am. J. Bot. 81: $1531-1537$

Wilson HD, Doebley J, Duvall M (1992) Chloroplast DNA diversity among wild and cultivated members of Cucurbita (Cucurbitaceae). Theor. Appl. Genet. 84: 859-865 